\title{
Indinavir/Low-dose Ritonavir Containing HAART in HIV-1 Infected Children has Potent Antiretroviral Activity, but is Associated with Side Effects and Frequent Discontinuation of Treatment
}

\author{
P.L.A. Fraaij, G. Verweel, A.M.C. van Rossum, N.G. Hartwig, D.M. Burger, R. de Groot
}

\begin{abstract}
We here present the study results of 21 HIV-1 infected children who were treated with indinavir plus low-dose ritonavir and two nucleoside reverse transcriptase inhibitors (NRTIs) for 48 weeks. Although this q12h HAART regimen had potent antiretroviral activity, it was frequently associated with side effects and discontinuation of therapy.
\end{abstract}

Infection 2007; 35: 186-189

DOI 10.1007/s15010-007-6068-1

\section{Introduction}

Indinavir is a potent protease inhibitor (PI), which has successfully been used in adults and children in combination with nucleoside reverse transcriptase inhibitors (NRTIs) to suppress HIV-1 infection [1, 2]. Durable suppression of HIV requires good adherence to the HAART regimen. Discontinuation or irregular use of HAART results in viral rebound, resistance of HIV to the medication and ultimately AIDS [3]. HAART regimens containing indinavir are difficult to adhere to. Indinavir, when used as a sole PI, must be administered three times daily (q8h), thus interfering with the sleeping time and school hours of children. In addition, food restrictions further complicate the regimen, since the drug needs to be taken on an empty stomach or with a low-caloric meal.

To ensure adherence to an indinavir-containing HAART regimen, less frequent and less complicated dosing schemes are required. An addition of low-dose ritonavir to indinavir increases plasma levels of indinavir allowing for a twice-daily medication scheme without the necessity for food restrictions $[4,5]$. Currently, no information on the long-term clinical efficacy and safety of this combination in children is available. Therefore, we performed an open uncontrolled pilot study in 21 HIV-1 infected children who were treated with indinavir and low-dose ritonavir containing HAART.

\section{Methods}

Children included in the Rotterdam cohort and treated with q8h-dosed HAART with indinavir as the sole PI were offered to change therapy to q12h-dosed HAART with indinavir and low-dose ritonavir [6]. In addition, between 2001 and 2002, HAART-containing indinavir and low-dose ritonavir were initiated in children naive to antiretroviral medication with a mean HIV RNA level $>5.000$ copies/ml and a CD4+ T-cell count below age-specific reference values. The study protocol was approved by the medical ethical committee of the Erasmus MC. Written and informed consent was obtained from parents and patients. The patients' medical histories, physical examinations and laboratory values were analyzed before the start of the medication and after $4,8,12,24,36$ and 48 weeks of treatment. After minimally 2 weeks of treatment, the steady-state pharmacokinetics of indinavir was determined [7]. This procedure was repeated when dosage adjustment of indinavir was necessary to normalize the area under the plasma concentration-time curve (AUC) to adult values.

Age-specific reference values for the CD4+T-cells were calculated by dividing the patient's individual value at the different time points by the median of the reference value at the different time points [8]. Differences between paired variables were analyzed with the Wilcoxon-signed rank test and between groups with the Mann-Whitney U-test. For statistical analysis of the data, SPSS $^{\odot} 12$ and Microsoft Excel ${ }^{\odot 97}$ software were used. 


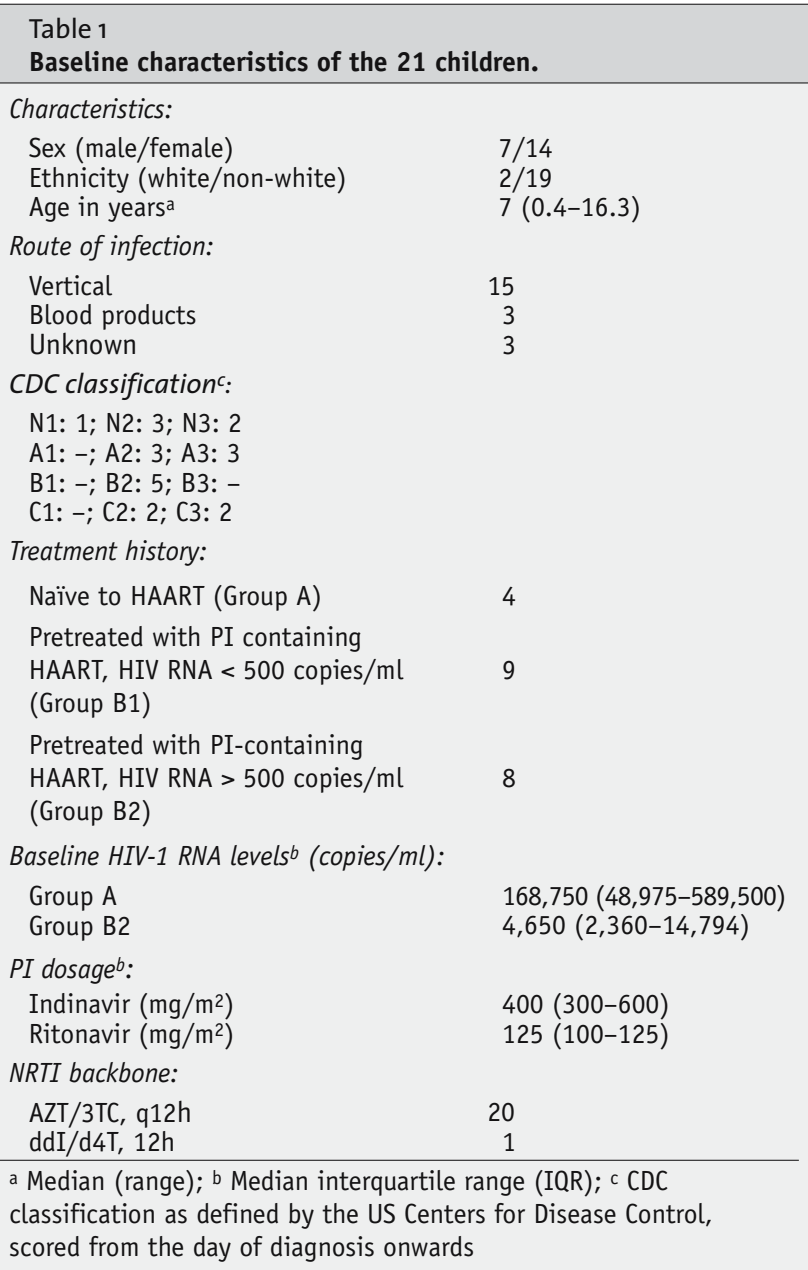

\section{Results}

A total of 21 children were enrolled in the study of which 16 completed the 48 weeks study period. The baseline characteristics of all patients are summarized in table 1. Four children were naive to antiretroviral therapy (Group A). Seventeen children had received prior indinavir-containing HAART for a median period of 18 months (range, 2-50 months). Of these, nine had baseline HIV-1 RNA levels below 500 copies/ml (Group B1) and eight had HIV-1 RNA levels above 500 copies/ml (Group B2). Indinavir was started at a median dosage of $400 \mathrm{mg} / \mathrm{m}^{2}$ (range 300-600) and ritonavir was started at a median dosage of $125 \mathrm{mg} / \mathrm{m}^{2}$ (range 100-125).

The clinical condition of the patients during the study period was good. None of the patients showed signs and symptoms of AIDS and no progression in their CDC-classification stage was observed. The course of the surrogate markers viral load and CD4 + T-cell counts during the follow-up are depicted in table 2. Overall after 48 weeks of treatment 13 out of the 16 children still on treatment had HIV-1 RNA levels $<500$ copies/ml and $11<50$ copies $/ \mathrm{ml}$.
In Group A, three out of four patients had HIV-1 RNA levels $<50$ copies after 48 weeks of treatment. In Group B1, seven out of eight patients had HIV-1 RNA levels $<50$ copies. In Group B2, three of four children had HIV-1 RNA levels $<500$ copies/ml, but only 1 had HIV-1 RNA levels $<50$ copies $/ \mathrm{ml}$. Over time an increase in CD4 + T-cells was observed, albeit not significant for any treatment group. (p-value baseline vs week 48 for the total group CD4\% total T-cells 0.234 and for CD4\% normal 0.14 ).

Most children $(n=19)$ reported side effects related to the medication. The adverse events occurred throughout the entire study period. These side effects were often mild and of gastrointestinal origin. However, serious adverse were reported in seven children. These included nephrolithiasis $(\mathrm{n}=2)$, silent nephrolithiasis found upon ultrasound research $(n=2)$, jaundice $(n=1)$, impaired liver functions, vomiting and malaise $(n=1)$ and dehydration due to vomiting $(\mathrm{n}=1)$. Serious side effects were observed in all study groups (Group A: 1, Group B1:3 and B2: 3) (Table 3).

Five patients stopped therapy during the follow-up period. In one additional patient medication was discontinued on the last study day. Discontinuation happened four times because of drug toxicity (1 nephrolithiasis, 1 silent nephrolithiasis, 1 rash, 1 hepatitis) and twice on patient request. All children that stopped medication were pretreated and most $(n=4)$ had detectable viral loads at the start of the study. These patients had suffered from indinavir related toxicity in the past. However, none of the adverse events that had occurred before the start of the study were serious (Table 4).

No significant differences were found between the PK parameters of children with or without side effects (data not shown). However, in two children renal side effects resolved after a decrease of the indinavir or ritonavir dosage. In the four children who discontinued medication because of side effects dosage adjustments were not performed. This was because of the seriousness of the side effects and hesitation in the patients and their parents to restart indinavir.

\section{Discussion}

The studied regimen had potent antiretroviral activity with suppression of HIV in most children who remained on therapy for 1 year. However, side effects occurred frequently. No clear relation between the height of PK parameters and side effects or discontinuation of therapy were found. Still, most children in our study received indinavir/ritonavir $400 / 125 \mathrm{mg} / \mathrm{m}^{2} \mathrm{q} 12 \mathrm{~h}$ which has been shown to result in significantly higher indinavir exposure compared to reference data of indinavir q8h in both adults and children [7]. This increased AUC may result in a higher incidence of side effects, especially when instructions to increase fluid intake are not sufficiently followed. This is of major concern since the occurrence of side effects poses a major threat to the adherence, whilst maintenance of adherence was the 
Table 2

Clinical en immunological parameters during 1-year follow-up of 21 children treated with indinavir/ritonavir.

\begin{tabular}{|c|c|c|c|c|c|}
\hline & Week 0 & Week 12 & Week 24 & Week 36 & Week 48 \\
\hline \multicolumn{6}{|l|}{ Total Group: } \\
\hline On treatment & 21 & 18 & 16 & 16 & 16 \\
\hline HIV-1 RNA levels $<500$ & $9(43 \%)$ & $13(72 \%)$ & $13(81 \%)$ & $14(88 \%)$ & $13(81 \%)$ \\
\hline HIV-1 RNA levels $<50$ & $6(29 \%)$ & $8(44 \%)$ & $10(63 \%)$ & $11(69 \%)$ & $11(69 \%))$ \\
\hline Median \%CD4a & $37(23-54)$ & $40(32-61)$ & $41(35-61)$ & $40(32-62)$ & $40(30-62)$ \\
\hline Median CD4\% normal ${ }^{\mathrm{a}}$ & $61(38-105)$ & $72(47-117)$ & $78(55-122)$ & $67(57-135)$ & $68(54-128)$ \\
\hline \multicolumn{6}{|l|}{ Group A: } \\
\hline On treatment & 4 & 4 & 4 & 4 & 4 \\
\hline HIV-1 RNA levels $<500$ & 0 & $3(75 \%)$ & $4(100 \%)$ & $3(75 \%)$ & $3(75 \%)$ \\
\hline HIV-1 RNA levels $<50$ & 0 & $1(25 \%)$ & $2(50 \%)$ & $3(75 \%)$ & $3(75 \%)$ \\
\hline Median \%CD4 a & $28(7-41)$ & $39(15-46)$ & $38(26-58)$ & $36(21-56)$ & $40(26-58)$ \\
\hline Median CD4\% normal ${ }^{\mathrm{a}}$ & $39(8-123)$ & $45(27-95)$ & $71(42-149)$ & $61(49-115)$ & $57(42-139)$ \\
\hline \multicolumn{6}{|l|}{ Group B1: } \\
\hline On treatment & 9 & 8 & 8 & 8 & 8 \\
\hline HIV-1 RNA levels $<500$ & $9(100 \%)$ & $6(75 \%)$ & $8(100 \%)$ & $8(100 \%)$ & $7(88 \%)$ \\
\hline HIV-1 RNA levels $<50$ & $6(67 \%)$ & $6(75 \%)$ & $8(100 \%)$ & $6(75 \%)$ & $7(88 \%)$ \\
\hline Median \%CD $4^{a}$ & $45(38-48)$ & $46(38-59)$ & $43(37-53)$ & $42(37-57)$ & $40(32-56)$ \\
\hline Median CD4\% normal ${ }^{\mathrm{a}}$ & $96(60-118)$ & $76(69-134)$ & $78(67-126)$ & $87(58-141)$ & $80(57-121)$ \\
\hline \multicolumn{6}{|l|}{ Group B2: } \\
\hline On treatment & 8 & 7 & 4 & 4 & 4 \\
\hline HIV-1 RNA levels $<500$ & 0 & $4(75 \%)$ & $1(25 \%)$ & $3(75 \%)$ & $3(75 \%)$ \\
\hline HIV-1 RNA levels $<50$ & 0 & $1(15 \%)$ & 0 & $2(50 \%)$ & $1(25 \%)$ \\
\hline Median $\% C D 4^{\mathrm{a}}$ & $24(19-46)$ & $33(29-61)$ & $34(22-53)$ & $40(27-53)$ & $41(25-52)$ \\
\hline Median CD4\% normal ${ }^{\mathrm{a}}$ & $53(27-68)$ & $69(51-124)$ & $83(48-122)$ & $100(54-143)$ & $90(49-205)$ \\
\hline
\end{tabular}

${ }^{a}$ Median (interquartile range). Group A: children naive to HAART, Group B1: PI experienced patients with HIV-1; RNA < 500 copies on baseline, Group B2: PI experienced patients with HIV-1 RNA > 500 copies on baseline

most important reason to perform this medication change. In addition, patients reported that the combination was not easy to take: the high pill burden and the bad taste of ritonavir liquid were considered as negative aspects of the new regimen. Side effects and intolerance to the medication resulted in a high number of children that discontinued the study regimen as compared to studies in children with new and easier to use HAART regimens. In a study on lopinavir/ritonavir-containing HAART in children only 2 out of 100 patients prematurely discontinued treatment [9]. However, one should be cautious to compare both studies, since the numbers of patients are relatively small and the studied patient population selected differently. Interest- ingly, a large proportion of children that discontinued medication in our study had detectable viral loads at baseline. Possibly, preexisting problems with adherence may have influenced our data: As a result of non-adherence plasma levels tent to fluctuate, which may induce side effects [10]. In addition non-adherent patients are more likely to be less motivated to continue medication and thus terminate study participation.

Because of the high number of side effects and patients that prematurely discontinued medication, we feel that newer and easier to use HAART regimens than indinavir/low-dose ritonavir should be used to treat HIV-1 infected children. However when these are not available indinavir combined 


\begin{tabular}{|c|c|c|c|}
\hline \multicolumn{4}{|c|}{$\begin{array}{l}\text { Table } 3 \\
\text { No significant difference in the occurrence of SAE's between } \\
\text { the three treatment groups: NPar tests occurrence of SAE's } \\
\chi^{2} \text {-test frequencies. }\end{array}$} \\
\hline & Observed $\mathrm{N}$ & Expected N & Residual \\
\hline \multicolumn{4}{|l|}{ Group A } \\
\hline SAE & 1 & 2.0 & 1.0 \\
\hline No SAE & 3 & 2.0 & 1.0 \\
\hline Total & 4 & & \\
\hline \multicolumn{4}{|l|}{ Group B1 } \\
\hline SAE & 3 & 4.5 & 1.5 \\
\hline No SAE & 6 & 4.5 & 1.5 \\
\hline Total & 9 & & \\
\hline \multicolumn{4}{|l|}{ Group B2 } \\
\hline SAE & 3 & 4.0 & 1.0 \\
\hline No SAE & 5 & 4.0 & 1.0 \\
\hline Total & 8 & & \\
\hline Test statistics & Group A & Group B1 & Group B2 \\
\hline$\chi^{2} \mathrm{a}, \mathrm{b}$ & 1.000 & 1.000 & 0.500 \\
\hline Df & 1 & 1 & 1 \\
\hline Asymp. Sig. & 0.317 & 0.317 & 0.480 \\
\hline \multicolumn{4}{|c|}{$\begin{array}{l}\text { a } 2 \text { cells }(100.0 \%) \text { have expected frequencies less than } 5 \text {. The } \\
\text { minimum expected cell frequency is } 2.0 ; \text { b } 2 \text { cells }(100.0 \%) \text { have } \\
\text { expected frequencies less than } 5 \text {. The minimum expected cell fre- } \\
\text { quency is } 4.5 ; \text { c } 2 \text { cells ( } 100.0 \%) \text { have expected frequencies less } \\
\text { than } 5 . \text { The minimum expected cell frequency is } 4.0\end{array}$} \\
\hline
\end{tabular}

with ritonavir can be considered as a treatment option for HIV-1 infected children.

\section{Financial Disclosure}

The authors have participated in studies that were financially supported by Merck Sharp and Dome, GlaxoSmithKline and the Aids Fonds, The Netherlands from 1997 to 1999. From 2002 until 2003, the studies received financial support from Merck Sharp and Dome, GlaxoSmithKline and Abbott. No other associations of the authors are reported that might pose a conflict of interest. There was no involvement of the previously mentioned sponsors in data collection, data analysis, the writing of this article, and article submission.

\section{References}

1. van Rossum AM, Geelen SP, Hartwig NG, Wolfs TF, Weemaes CM, Scherpbier HJ, et al.: Results of 2 years of treatment with protease-inhibitor-containing antiretroviral therapy in Dutch children infected with human immunodeficiency virus type 1. Clin Infect Dis 2002; 34: 1008-1016.

2. Gulick RM, Mellors JW, Havlir D, Eron JJ, Meibohm A, Condra JH, et al.: 3-year suppression of HIV viremia with indinavir, zidovudine, and lamivudine. Ann Intern Med 2000; 133: 35-39.

3. Deeks SG: Treatment of antiretroviral-drug-resistant HIV-1 infection. Lancet 2003; 362: 2002-2011.

4. Hsu A, Granneman GR, Cao G, Carothers L, Japour A, El-Shourbagy $\mathrm{T}$, et al.: Pharmacokinetic interaction between ritonavir and
Table 4

Study termination and viral load at start of the study: NPar tests $\chi^{2}$-test frequencies.

\begin{tabular}{|c|c|c|c|}
\hline & Observed $\mathrm{N}$ & Expected $\mathrm{N}$ & Residual \\
\hline \multicolumn{4}{|l|}{ Group B1 } \\
\hline $\begin{array}{l}\text { Terminated study } \\
\text { medication }\end{array}$ & 2 & 4.5 & 2.5 \\
\hline $\begin{array}{l}\text { Did not terminate } \\
\text { study medication }\end{array}$ & 7 & 4.8 & 2.5 \\
\hline Total & 9 & & \\
\hline \multicolumn{4}{|l|}{ Group B2 } \\
\hline $\begin{array}{l}\text { Terminated study } \\
\text { medication }\end{array}$ & 4 & 4.0 & 0.0 \\
\hline $\begin{array}{l}\text { Did not terminate } \\
\text { study medication }\end{array}$ & 4 & 4.0 & 0.0 \\
\hline Total & 8 & & \\
\hline Test statistics & Group B1 & Group B2 & \\
\hline$\chi^{2 a, b}$ & 2.778 & 0.000 & \\
\hline Df & 1 & 1 & \\
\hline Asymp. Sig. & 0.096 & 1.000 & \\
\hline
\end{tabular}

indinavir in healthy volunteers. Antimicrob Agents Chemother 1998; 42: 2784-2791.

5. van Rossum AM, de Groot R, Hartwig NG, Weemaes CM, Head S, Burger DM: Pharmacokinetics of indinavir and low-dose ritonavir in children with HIV-1 infection. AIDS 2000; 14: 2209-2210.

6. Burger DM, van Rossum AM, Hugen PW, Suur MH, Hartwig NG, Geelen SP, et al.: Pharmacokinetics of the protease inhibitor indinavir in human immunodeficiency virus type 1-infected children. Antimicrob Agents Chemother 2001; 45: 701-705.

7. Bergshoeff AS, Fraaij PL, van Rossum AM, Verweel G, Wynne LH, Winchell GA, et al.: Pharmacokinetics of indinavir combined with low-dose ritonavir in human immunodeficiency virus type 1-infected children. Antimicrob Agents Chemother 2004; 48: 1904-1907.

8. Comans-Bitter WM, de Groot R, van den Beemd R, Neijens HJ, Hop WC, Groeneveld K, et al.: Immunophenotyping of blood lymphocytes in childhood. Reference values for lymphocyte subpopulations. J Pediatr 1997; 130: 388-393.

9. Saez-Llorens X, Violari A, Deetz CO, Rode RA, Gomez P, Handelsman E, et al.: Forty-eight-week evaluation of lopinavir/ ritonavir, a new protease inhibitor, in human immunodeficiency virus-infected children. Pediatr Infect Dis J 2003; 22: 216-224.

10. Fraaij PL, van Kampen JJ, Burger DM de Groot R: Pharmacokinetics of antiretroviral therapy in HIV-1-infected children. Clin Pharmacokinet. 2005; 44: 935-956. 